only to give a rough idea of the prominence variations based on a repetition of the observations of $1872-1885$. The last curves, namely, those marked $\mathrm{D}$, represent the variation from year to year of the total spotted area on each hemisphere of the sun. The vertical broken and continuous lines indicate the epochs of sun-spot minima and maxima as determined by combining the amount of spotted area on both hemispheres of the sun.

Considering now the curves marked $\mathrm{A}$, the following general deductions may be made :-

From sun-spot minimum to minimum there are three, but generally four, distinct " spot-activity tracks," or loci of movements of the centres of action of spot disturbance.

The first appearance of each of these " spot-activity tracks" occurs generally between a sun-spot minimum and the following maximum. After about the epoch of maximum no new "spot-activity tracks" of large magnitude are generally commenced.

Their first appearance is mostly in higher latitudes than $20^{\circ}$ in each hemisphere.

They are faintly indicated at first, become more prominent and distinct, and finally thin out and fade away.

They all fade away in regions close to the equator.

There seems to be a tendency for each successive "spotactivity track" to make its appearance in latitudes higher than the one preceding it.

At, or a little after, the time of sun-spot maximum there is also a tendency for each "spot-activity track" to retain its latitude for a short time.

It is interesting now to examine these curves (A) in relation to those marked $\mathrm{B}$, which, as previously pointed out, represent the drift from year to year of the mean heliographic spot latitude and illustrate Spörer's "law of zones." These latter (curves B) are individually really nothing more than the integration of the corresponding curves A. Every change of curvature in curves $B$ is due to either the outburst of spots in another "spot-activity track" or to one "spot-activity track" becoming more intensified in relation to another, or, lastly, to the extinction of a "spot-activity track" as the equator has been reached, as shown in the curves A.

To illustrate this, let the curve for the mean heliographic spot latitude in the southern hemisphere (curves B) beginning in the year 1879 be considered. This is practically the period referred to above by Dr. Braun.

At this time there is only one "spot-activity track" (latitude $22^{\circ}$ ) in existence, as shown in curve A, so curve $\mathrm{B}$ consequently commences in the same latitude. By the next year the " spot-activity track" (curves A) has reached latitude $17^{\circ}$, and a new one has made its appearance in latitude $25^{\circ}$. Curve $\mathrm{B}$, therefore, takes the mean position of about $20^{\circ}$ when allowance has been made for the difference of intensity of these two tracks.

In the following year, 1881, both these "spot-activity tracks" have approached nearer the equator, but another has appeared in latitude $25^{\circ}$, so that the mean latitude for the whole hemisphere has only slightiy changed.

By the year I 882 still another "spot-activity track" has come into existence in latitude $28^{\circ}$, while the first "spotactivity track" mentioned above has vanished. The mean latitude for the whole hemisphere, as is indicated in curve $\mathrm{B}$ for this epoch, is increased to latitude $20^{\circ}$. After this all three "spot-activity tracks" approach the equator, and curve $B$ does the same, but owing to the relative changes in the amount of the spotted area in each of these "spotactivity tracks," as indicated by their thickness, the mean heliographic latitude curve suffers another change of curvature in 1885 . In a similar way the various changes of curvature in all the other curves (curves B) can be accounted for.

Particular attention has been directed above to the fact that about the times of sun-spot maxima there is considerable spot-activity in the highest spot latitudes, which according to Spörer's law would not be expected. If reference be made to the sun-spot observations of Messrs. De La Rue, Stewart, Lœwy, and also to those by the Wilna observers, it will be seen that as early as 1872 it was pointed out, as an unlooked for fact, that at the sun-spot maximum of I87I numerous spots appeared in high (spot) latitudes.

Finally, if a comparison be made between the curves A and $\mathrm{C}$ it will be seen that from the time of a sun-spot minimum, when the "prominence-activity tracks" are approaching more rapidly high latitudes, up to about a sunspot maximum, when they reach their highest positions, nearly all the "spot-activity tracks" come into existence. Further, the nearer the " prominence-activity tracks" approach the poles the higher in latitude do these "spotactivity tracks" make their appearance, and this is the case for each hemisphere of the sun separately.

What the actual connection between these two different systems of currents is, it is not possible yet to say, but these facts siggest a close relationship.

The result of the present investigation thus leads to the following conclusions:-

(I) Spörer's law of spot zones is only approximately true, and gives only a very general idea of sun-spot circulation.

(2) Spörer's curves are the integrated result of two, three, and sometimes four "spot-activity track" curves, each of the latter falling nearly continuously in latitude.

(3) Spörer's and many other previous reductions have indicated the peculiar "wavy" nature of the integrated curve, which peculiarity is here shown to be for the most part real and not due to errors of observation, \&c.

(4) Outbursts of spots in high latitudes are not restricted simply to the epochs at or about a sun-spot minimum, but occur even up to the time of sun-spot maximum.

(5) The successive commencement of the " spot-activity tracks " in higher latitudes between a sun-spot minimum and maximum seems to be closely related to the "prominence-activity tracks" at these periods.

$$
\text { William J. S. Lockyer. }
$$

\section{THE DUNEDIN MEETING OF THE AUSTRALASIAN ASSOCIATION.}

THE tenth session of the Australasian Association for the Advancement of Science was opened at Dunedin, New Zeatand, on January 6 , under the patronage of His Excellency the Earl of Ranfurly, the Governor of New Zealand, who took the chair at the inaugural meeting in the absence of the past president, Captain F. W. Hutton, F.R.S., whom ill-health prevented from attending.

The president, Prof. 'T. W. E. David, F.R.S., of Sydney, took as the subject of his address, "The Aims and Ideals of Australasian Science." Although this was wholly local in immediate interest, it was an extremely valuable epitome of the work already done by Australasian men of science. $\mathrm{He}$ dwelt upon the value of organisation in scientific research, and of the investigations carried out by research committees appointed at the meetings of the Australasian Association for the Advancement of Science. He applauded the good work done by the New Zealand Grovernment in the preservation of the fauna and flora of New Zealand by the establishment of reserves, as well as in the establishment of a magnetic observatory at Christchurch, and urged the Commonwealth and State Governments of Australia to follow this lead.

In discussing the "Aims and Ideals," Prof. David, amongst other matters, referred to the proposed establishment in New South Wales of a branch of the Lick Observatory, to the importance of investigating the nature of the aurora australis, of carrying out a geodetic survey of Australia, and of continuing to support the high-level meteorological stations on Mt. Koscuisko. He insisted on the crying need for a systematic geological survey of New Zealand, and for the identification by competent palæontologists of the numerous fossils now stored in the Colonial Museum at Wellington, where there are "30,000 specimens in the museum cases, most of which are unnamed, and in the cellars about 500 unopened boxes full of undescribed fossils."

The president is of opinion that "nowhere in the southern hemisphere is there such a thorough and complete record of the succession of animal and plant life from the close of the Palæozoic time up to the present as in New Zealand, and nowhere else is there evidence of such a wonderful range of the Spiriferidæ high up in the Mesozoic rocks."

That important line of work in modern geology, viz. " the No. I793, voL. 69] 
reading of the past geographical history of a country from a study of its surface features," has already found exponents in Australia; it must be continued also in New Zealand. $\mathrm{He}$ went on to refer to the "wonderfully developed alkaline series of eruptive rocks" which have been and are at present receiving attention in various parts of Australasia, and characterised the tuffs around Dunedin as being "one of the most interesting groups of its kind in the world."

In biology he dealt with Mr. Chas. Hedley's important study of the molluscan fauna in the ocean near the edge of the continental shelf of East Australia, and pointed out the desirability of examining this fauna off the shore of New Zealand (a committee was later appointed to initiate this investigation).

Prof. David passed on to the importance of marine biological stations, and expressed his satisfaction that recently the New Zealand Government, at the instance and with the aid of the Otago Institute and the Otago Acclimatisation Society, had already established such a station near Dunedin. He reviewed some of the more important recent work by various biologists on the fauna and flora of Australasia, and noted the publication, under the editorship of Captain Hutton, of the "Index Faunæ. Novœ Zealandix."

In reference to geography, he naturally looked forward to interesting results from the work of the various Antarctic expeditions as bearing on the former extension and connection of these southern lands. After dealing with the oceano-geographical work that has recently been carried out off the Australian coast, Prof. David expressed the opinion " that it would be possible to put a bore down in the bed of the ocean at a depth of about Ioo fathoms, and in such a way as to secure a core of the strata encountered. If the boring at these shallower depths were successful, attempts would be made to bore at greater depths."

In discussing agricultural studies, he stated that " an important fact of late brought into prominence is that the barren-looking red soils of the west plains of New South Wales are formed of material which is exceptionally rich in mineral plant food." After indicating other lines of work which ought to be carried out, the president insisted that the importance of science to national wealth can scarcely be overestimated, but the advance of education should be our grandest ideal."

He then turned to the "duty of the association in science teaching," quoting Sir Norman Lockyer's address to the British Association, as well as the reports, lectures and writings on the subject by various Australasian men of science, and emphasised the need of carefully thought out schemes of science teaching in elementary schools along "heuristic" lines.

As an outcome of the address a committee was appointed to inquire into the science teaching of these colonies, and to suggest a way in which it could be made effective in primary and secondary schools, colleges and universities.

The following are the authors and titles of the presidential addresses to sections :- Prof. W. H. Bragg, of Adelaide, some recent advances in the ionisation of gases; $\mathrm{Mr}$. Brownlie Henderson, of Brisbane, chemistry and food; $\mathrm{Mr}$. W. H. Twelvetrees, of Tasmania, some aspects of modern petrology ; Colonel Legge, of Tasmania, on the relationship of the avifauna of Australasia with that of Austro-Malayan and Polynesian regions; Prof. Baldwin Spencer, F.R.S. of Melbourne, dealt with totemism in Australia; Mr. T. W. Kirk, Government biologist, Wellington (in the ábsence of the president), gave a short account of the importance of agriculture. The president of the section for architecture and engineering, Mr. H. Deane, engineer-in-chief of railway construction in New South Wales, discussed day labour on Government works; Dr. Frank Tidswell, of the Department of Public Health, Sydney, spoke on the hygienic aspect of boric acid; Mr. John Shirley, chief inspector of schools, Brisbane, took education and national trade competition, in the mental science and education section; and Prof. J. W. Gregory, F.R.S., of Melbourne, discussed the Southern Ocean and its climatic control over Australasia.

Among the papers read before the various sections, the following are of more than local importance:-Dr. roleridge Farr, of the Christchurch Magnetic Observatory, on some continuous observations on the rate of dissipation of electrical charges in the open air, showed that in ordinary weather the atmosphere is a better conductor for negative than for positive charges, but during the "Canterbury nor'-westers " the reverse is the case.

A communication on the heating effect of radium emanation, by Prof. Rutherford, was presented.

Dr. Greig Smith, of Sydney, in a paper on the production and identification of vegetable gums, showed that some gums are the products of certain bacteria, which inhabit the tissues of the gum-bearing trees. The bacteria were isolated and made to produce their gums in the laboratory. Thus " arabin," the soluble gum of wattles, "metarabin," the insoluble gum of wattles and of certain fruit trees, and "pararabin," the insoluble constituent of Sterculia gum, are each produced by a distinct bacterium. The author suggests that all other vegetable gums are bacterial products, and that the world's supply of gum might be increased by judicious injection of susceptible trees.

Prof. Easterfield and Mr. G. Bagley (Wellington), in the chemistry of colophony, raised the question whether any particular chemical structure is common to the resin acids obtained from coniferous trees.

Prof. Easterfield and Mr. B. C. Aston, in the acids of some New Zealand timber trees, find that the resinous matter contains crystalline constituents, to which the name "rimuic acid" is given, closely related to "podocarpic acid," which occurs in one of the timber trees of Java.

In the geology section, Dr. P. Marshall (Dunedin) described a trachydolerite from Dunedin; this rock, which has a very peculiar association of minerals, belongs to a rare type, which has been described also from East Africa.

An important note on the geology of the New Hebrides, by Mr. D. Mawson, showed that at Sandwich Island there is a series of raised coral reefs, at least nine in number, up to a height of 2000 feet above sea-level. The coral rock occurs as a mere veneer over fine-grained submarine tufaceous muds, like "Fiji soapstone," or over other volcanic rocks. At Santo three unconformable series of rocks were discovered, the oldest of which is a tufaceous calcareous group, dipping off the syenites at an angle of $50^{\circ}$; this contains vast numbers of foraminifera (Orbitoides), showing that the oldest rocks in the New Hebrides are not older than Tertiary.

In Section D, Miss G. Sweet described the structure of the eye of Notoryctes, the marsupial mole. The eye has sunk below the surface, and is merely represented by the pigmented choroid, all trace of iris, lens, retina and optic nerve having practically disappeared. The lachrymal gland, however, is of great size, and opens into a closed conjunctival sac, derived from the closure of the eyelids of the eye-vestige; thence the naso-lachrymal duct takes the usual course.

Prof. Chilton, of Christchurch, read papers on some subterranean isopods.

In the anthropological section, Mr. E. Tregear, of Wellington, in a paper on the language of Maori and Malay, drew a comparison between the language of Celebes islanders and that of the Polynesian; a considerable number of words are identical in the two languages, too great to be a coincidence, suggesting, probably, a derivation from a common ancestral language or from one another.

Prof. Baldwin Spencer gave an account of fire ceremonies. in Australia.

In the agricultural section, Mr. J. A. Gilruth, Wellington, read a note, and gave a demonstration, of a means of making innocuous injections of virulent cultures of anthrax. This he does by inoculation with a mixture of the culture of anthrax bacillus with some non-pathogenic microbe, in certain proportions. He also pointed out the toxic effects of ragwort (Senecio jacobaea) upon cattle and horses, resulting in a disease known in Nova Scotia as "Picton disease," and in New Zealand as "Winton disease." Sheep can eat the weed with impunity, but direct experiments show that in the case of cattle and horses inflammation of the liver ensues, which causes death.

An evening lecture was given by Prof. Baldwin Spencer on the Central Australian aborigines, their habits and customs. This was illustrated by numerous lantern slides showing the aborigine from infancy to old age, and by 
kinematographic and phonographic records of corroborees and ceremonies. The lecture was an outcome of two journeys with Mr. Gillen from Adelaide to the Gulf of Carpentaria; the most important ceremony, not dealt with in their book, referred to certain burial customs, notably the removal of the bones from their first " tree-grave," their burial in an ant-hill, but the reservation of one arm-bone for future elaborate ceremonial, which was shown by the kinematograph.

The session, at which nearly rooo members and associates were present, closed on January 13.

At the close" of the session the "Marine Fish Hatchery and Biological Station," situated in the Otago Harbour, was visited and formally opened, although it is not yet complete. The establishment of this, the first biological station in Australasia, is the outcome of the persistent efforts of Mr. Geo. M. Thomson, of Dunedin.

On the following day a small party-Mr. Hedley, Prof. Benham, and Prof. Kirk-made an excursion to the edge of the " continental shelf," which is about I5 miles due east of the Otago Head, but owing to the rough sea part of the deep-sea dredging gear was carried away as it was being hauled up, and later efforts with other gear resulted in but a small reward for the day's work. The association has made a grant for pursuing this work.

\section{BREWING AND RESEARCH. ${ }^{1}$}

${ }^{N}$ Igor the great brewing firm of Messrs. Guinness in Dublin instituted a research laboratory, in which the work has been conducted by four trained investigators under the direction of Dr. Horace T. Brown. With characteristic generosity, Messrs. Guinness have rendered the results so far obtained available for other workers in the same field by the publication of a first volume of Transactions. Appreciation of these results will by no means be confined to the circle of scientific men technically interested in brewing, for Messrs. Guinness' investigators have been seeking for that exact knowledge which is of permanent scientific value and at the same time affords a basis whereon technical process can be built with some degree of confidence and promise. The problems of the brewer really appeal to a very wide circle; because they are the problems involved in the biological chemistry of the germinating plant and of the yeasts and other lower organisms, they become the problems of the plant physiologist, of the agricultural chemist, and even of the animal physiologist. As Dr. Brown says in his preface, "Could we determine, in the early stages of the germination of a grain of barley, all the 'down grade' chemical changes of the nitrogenous substances stored in the endosperm, and follow the products as they enter the embryonic plant and are once more built up into proteid, we should have a key to many obscure problems connected with the life processes of plants and animals."

The first problem dealt with in the present volume is the investigation of the nitrogenous constituents of malt, i.e. of the soluble bodies which are formed by the hydrolysis of the barley proteid under the action of the enzymes produced during germination, or which may turn out to be built up from simpler substances as the new plant develops. No one who has not worked amongst that maze of bodies generally "lumped" as amides can appreciate the thick darkness which envelops their separation, and consequently all attempts to appreciate their physiological significance. In the first place Dr. Brown decided upon a critical examination of the various processes which have been proposed for the determination of bodies of the amide and amino acid type; none of the previous results, not even those of Schultze, hitherto the chief worker in this field, have been accepted without examination, and the figures given show the need for revision that existed.

As a result, the Sachsse method, which depends on the hydrolysis of the amide group, and the Sachsse-Korman method, which depends on the reaction of the amide and amino group with nitrous acid, have been improved unti they are capable of giving exact results, as tested with pure

1 Transactions of the Guinness Research Laboratory, vol. i. part i. Pp. 14ז. (1903.)

NO. I793, VOL. 69] specimens of asparagin, aspartic acid, glutamic acid, leucine, tyrosine, alanine, \&c. Thus by a combination of the two methods the amount of nitrogen present in a complex mixture as amide and as amino acid can be distinguished and determined. A novel and exact method for the direct determination of tyrosine in such mixtures has also been devised.

Much yet remains to be done before each one of these bodies can be estimated separately, probably, as Dr. Brown indicates, by the application of E. Fischer's esterification method, but the processes here set out with careful detail will be of the greatest possible service to othar workers in plant chemistry.

Another old stumbling block has been the want of an accurate method for the estimation of so fundamental a substance as starch; O'Sullivan's method is exact enough, but is too prolonged to be anything but a research method, whereas it is often desirable to repeat starch determinations by the dozen. The volume contains a critical examination of a new starch method, which depends on a preliminary removal of the reducing sugars, \&c., with alcohol, followed by hydrolysis to the standard conditions which have already been laid down by Brown and Morris, whereupon the maltose is determined by its cupric reducing power. This method is likely to be of general service in the analysis of a large number of bodies containing starch.

Finally, the volume contains an examination from the plant physiological side of the factors associated with "quality" in barley, including an interesting cytological test of maturation.

The standard of the work recorded in these papers is so high, and their value so great to all others who are engaged with the chemistry of the plant and plant products, that we can only again express our thanks to Dr. Brown and his co-workers, and to Messrs. Guinness for allowing the record of their investigations to be made public. Would there were many great industrial firms with the same enlightened views on research!

A. D. $\mathrm{H}$.

\section{MARINE BIOLOGY}

THE number of the Journal of the Marine Biological Association recently issued (new series, vol. vi., No. 4) contains a detailed report on the trawling and other investigations carried out by the association in the bays on the south-east coast of Devon during 1901 to 1902 . The report has been prepared for the information of the Devon Sea Fisheries Committee by Mr. Walter Garstang, the naturalist in charge of the fishery investigations of the association, and is based upon a series of experimental trawlings and fish-marking experiments carried out by Dr. H. M. Kyle. The bays investigated are at present closed to trawlers, and as this closure has been found to press some what hardly on the smaller fishermen, the Sea Fisheries Committee were anxious to ascertain to what extent it was likely to be beneficial to the fisheries of the district as a whole. The general conclusion arrived at in the report is that, having regard to the permarient maintenance of the fishery, it would appear to be highly inadvisable to rescind the regulation which prohibits trawling in Teignmouth Bay and Torbay, where small fish congregate. On the other hand, there are no biological reasons against the reopening of Start Bay, since small fish are found in inappreciable numbers, whilst large plaice concentrate there during the autumn months.

A particular feature of these experiments was the success attained in the study of the migrations of plaice by marking individual fishes, which were subsequently recovered by the fishermen. Of 349 fish 9 inches and upwards in length marked and liberated in the bays, 96 were subsequently recovered, that is, 27.5 per cent., whilst of 71 fish liberated outside the bays 25 were recovered, or 35.2 per cent. The fishes had in many cases travelled considerable distances.

To the same number of the Journal Dr. Petersen, of Copenhagen, contributes a paper entitled "What is: Overfishing?" in which an attempt is made to define the problem now receiving so much attention from those responsible for fishery administration. Dr. Kyle furnishes notes on the physical conditions existing within the line from Start Point to Portland, and a paper on fishing nets, 